\title{
Early proximal lung cancer diagnosis and treatment
}

\author{
A. McWilliams*, B. Lam ${ }^{\#}$ and T. Sutedja
}

ABSTRACT: Lung cancer remains the largest cause of cancer deaths worldwide and the overall 5 -yr survival rate is only $15 \%$. This is because the majority of the lung cancers are diagnosed at late stages and the treatment outcome is suboptimal. However, the survival of patients with early stage proximal lung cancer is excellent and with advancements in technology we are currently well equipped to diagnose and stage these lung cancers. Together with the application of local bronchoscopic therapeutic modalities that may potentially cure early stage intraluminal lesions, there is expanding interest in the further exploration of new avenues for early detection, localisation, staging, treatment and close surveillance of these high-risk patients who are suffering from chronic field carcinogenesis. The present article will deal with various issues regarding early detection, staging and treatment of centrally located early stage, mostly squamous type, lung cancer.

ung cancer remains the largest cause of cancer deaths worldwide and the overall 5 -yr survival rate is only $15 \%$, despite many advances in imaging techniques and oncological care over the last few decades [1]. The largest gain in life expectancy in lung cancer patients has been among those with localised disease versus those with regional or distant metastasis [2]. However, only 19\% of lung cancers are localised at the time of diagnosis [2].

Lung cancer consists of a number of histological subtypes that are preferentially located in different parts of the tracheobronchial tree, i.e. central bronchial cancers tend to be squamous or small cell carcinoma types, and peripheral lung cancers tend to be adenocarcinoma and neuroendocrine cell types. Squamous cell carcinoma still accounts for $40-50 \%$ of lung cancers in males and $20-30 \%$ in females [3]. Early central squamous carcinoma in situ (stage 0) is difficult to detect and has the additional risk of being potentially multifocal, with up to $30 \%$ patients developing synchronous or metachronous lesions [4-15]. However, the survival of patients with small central lung cancers is excellent with 5-yr survival $>90 \%$ [610]. Despite the challenges of detecting this disease, the development of strategies to detect and treat these early stage central cancers may have an important impact on patient survival.

There has been considerable controversy regarding the invasive potential of squamous cell carcinoma in situ and the need for curative treatment $[9,11]$. Retrospective analysis of untreated patients with radiologically occult central lung cancer has revealed much lower 5-yr survival rates compared with surgically treated cases, in whom $>90 \%$ survival at 5 yrs can be achieved [4]. As squamous carcinoma in situ is difficult to detect and is often diagnosed by chance, only limited data are available regarding the natural history of these lesions [5]. In addition, most centres treat the lesions at the time of detection rather than await the development of invasion [7-11]. Reported progression rates to invasive cancer vary from $20 \%$ to $67 \%$ despite bronchoscopic therapy in some instances [16-19]. In one published study of observation without intervention, the overall progression of carcinoma in situ to invasive cancer was $21 \%$ over 4-17 months [20]. However, if lesions with completed follow-up only were evaluated, the observed progression rate was $\geqslant 33 \%$ (data included severe dysplasia) and half of the lesions that progressed were incurable [20].

Previous articles in this series: No. 1: De Wever W, Stroobants S, Coolen J, Verschakelen JA. Integrated PET/CT in the staging of nonsmall cell lung cancer: technical aspects and clinical integration. Eur Respir J 2009; 33: 201-212. No. 2: Rami-Porta R, Tsuboi M. Sublobar resection for lung cancer. Eur Respir J 2009; 33: 426-435.

\section{AFFILIATIONS}

*British Columbia Cancer Agency and Dept of Respiratory Medicine Vancouver General Hospital,

Vancouver, BC, Canada.

${ }^{*}$ Dept of Medicine, University of Hong Kong, Hong Kong SAR, China. 'Dept of Pulmonary Medicine, VU Academic Medical Center, Amsterdam, The Netherlands.

\section{CORRESPONDENCE}

A. McWilliams

University of British Columbia British Columbia Cancer Agency and Vancouver General Hospital 675 West 10th Avenue Vancouver $\mathrm{BC}$ V5Z 1L3 Canada

Fax: 16046758099

E-mail: amcwilli@bccancer.bc.ca

Received:

August 122008

Accepted:

August 202008

STATEMENT OF INTEREST

None declared. 
Therefore, the delay of treatment of these lesions seems likely to be detrimental, particularly in a patient with reasonable life expectancy.

However, early proximal lung cancer only represents a small proportion of lung cancer diagnosed in the clinical setting [21]. If more lung cancers could be diagnosed at this stage, the prognosis of lung cancer might be improved. With the advancements in technology, we are currently well equipped for the early detection and staging of these early stage proximal squamous type lung cancers. Together with application of local bronchoscopic therapeutic modalities that may potentially cure early stage intraluminal lesions [22], there is expanding interest in exploring new avenues for early detection, localisation, staging, treatment and close surveillance of these high-risk patients who are suffering from chronic field carcinogenesis. The present article will deal with various issues regarding early detection, staging and treatment of centrally located early stage, mostly squamous type, lung cancer.

\section{NONINVASIVE DETECTION OF EARLY PROXIMAL LUNG CANCER}

\section{Sputum cytology}

Sputum contains exfoliated airway epithelial cells and morphological analysis of sputum by cytology has been used for the early diagnosis of lung cancer, particularly central airway tumours, i.e. squamous cell carcinoma [22]. However, because of the low percentage of bronchial epithelial cells in sputum or inadequate preparatory techniques, the sensitivity is usually low [23]. Induced sputum has found to be better than spontaneous sputum [24] and the ThinPrep technique has been shown to improve diagnostic accuracy by reducing the unsatisfactory and false-negative rates by a total of 30\% [25]. The other limiting factor is the skill required for identifying subtle morphological abnormalities in cells; this results in significant variation in intra- and interobserver agreement in determining cancer cells [26]. Besides the above limitations, a recently published paper demonstrated that, although sputum cytological atypia predicted incidence of lung cancer, especially squamous cell lung cancer, this was a late event as the association was stronger for samples collected within 5 months of the diagnosis of lung cancer [27].

\section{Sputum cytometry}

Malignancy-associated change (MAC) is the change in the distribution of DNA in the nuclei of cytologically normal cells in the vicinity of pre-invasive or invasive cancer [28, 29]. It has been shown that the frequency of bronchial epithelial cells expressing MAC can be used to differentiate normal from lung cancer patients [30]. Computer-assisted sputum DNA analysis is the method used to detect MAC in exfoliated cells in sputum. By using either spontaneous sputum or induced sputum, PALCIC et al. [31] have found that sputum cytometry was not superior to that of conventional cytology in detecting early stage squamous cell lung cancer. By using induced sputum, a European study has shown that the sensitivity of sputum cytometry was 100\% for all stages of squamous cell lung cancer, while the sensitivity of conventional sputum cytology was only $10 \%$ [32]. However, in the latter study, only subjects with severe dysplasia or higher grade changes on cytological examination or grade II on DNA image cytometry were called for bronchoscopy. A selection bias might have occurred and, as longitudinal data were not available, its true sensitivity could not be defined. A recently published study has found that sputum cytometry was two times more sensitive than cytology in detecting either squamous cell lung cancer or central type of lung cancer [33]. However, as one-third of the study population were eventually found to have lung cancer, the performance of sputum cytometry could not be extrapolated to a lower risk population, i.e. in a screening setting. The performance of cytometry was compared with cytology in a lung cancer case finding study in radon-exposed uranium miners [34]. Sputum (spontaneous or via induction) were collected from 1,500 subjects. Lung cancers were found in $1.5 \%$ of the subjects and two-thirds had squamous cell lung cancer. There was no difference in either sensitivity or specificity of the two tests, though it should be noted that both the sensitivity and specificity of conventional sputum cytology in the study were very high.

\section{MINIMALLY INVASIVE DETECTION OF EARLY PROXIMAL LUNG CANCER}

The development of flexible fibreoptic white light bronchoscopy $\sim 40$ yrs ago has resulted in the availability of sophisticated tools for the assessment of the central airway mucosa [35-37]. Technological advancement has greatly improved image resolution and quality. However, early central lung cancers remain difficult to detect with white light bronchoscopy, even if it is compared with the improved images of video bronchoscopy [35]. A number of other white light imaging improvements are presently being evaluated, including optical zoom or magnifying lenses that may enhance the examination of the bronchial mucosa and improve the detection of early vascular changes that can be associated with early malignant change [36].

There are other developments that can be used along with white light imaging for localisation of pre-neoplastic lesions and early lung cancer utilising light outside the visible spectrum. These include autofluorescence-reflectance imaging, narrow band imaging and optical coherence tomography. Endobronchial ultrasound is another new technology that may assist in the evaluation of early central lung cancers.

\section{Autofluorescence-reflectance bronchoscopy}

The detection of pre-neoplastic lesions and carcinoma in situ is significantly increased with the use of autofluorescence imaging with white light bronchoscopy (table 1) [37-57]. Autofluorescence-reflectance bronchoscopy (AFB) has also been shown to have an important impact on the staging of potentially curable central lung cancers prior to endobronchial therapy, by enabling the bronchoscopist to obtain a more accurate assessment of the lesion size and margins [57-59].

Autofluorescence imaging utilises the spectral differences in fluorescence and absorption properties of normal and dysplastic bronchial epithelium. These differences have been the basis for the design of several autofluorescence imaging devices [40, $43,47]$. More recently, these devices have used a combination of reflectance and fluorescence for imaging $[42,54,59,60]$.

AFB was first developed at the British Columbia Cancer Research Centre (Vancouver, BC, Canada) and became commercially available in 1998 [46]. The original LIFE-Lung ${ }^{\circledR}$ system (Xillix Technologies, Vancouver, BC, Canada) used a helium-cadmium laser for illumination (442 nm) and detected 


\begin{tabular}{|c|c|c|c|c|c|c|}
\hline TABLE 1 & $\begin{array}{l}\text { entre trials } \\
\text { torescenc }\end{array}$ & $\begin{array}{l}\text { and rand } \\
\text { broncho }\end{array}$ & $\begin{array}{l}\text { omise } \\
\text { scopy }\end{array}$ & d stuc & ies of & \\
\hline \multirow[t]{2}{*}{ Study } & \multirow[t]{2}{*}{ System } & \multirow[t]{2}{*}{$\begin{array}{c}\text { Subjects } \\
n\end{array}$} & \multicolumn{2}{|c|}{$\begin{array}{c}\text { Sensitivity } \\
\%\end{array}$} & \multicolumn{2}{|c|}{$\begin{array}{c}\text { Specificity } \\
\%\end{array}$} \\
\hline & & & WLB & AFB & WLB & AFB \\
\hline LAM [38] & LIFE-Lung & 173 & 9 & 66 & 90 & 66 \\
\hline ERNST [39] & D-Light & 293 & 11 & 66 & 95 & 73 \\
\hline EdeLL [40] & Onco-LIFE & 170 & 10 & 44 & 94 & 75 \\
\hline HIRSCH [41] & LIFE-Lung & 55 & 18 & 73 & 78 & 46 \\
\hline HÄUSSINGER [42] & D-Light & 1173 & 58 & 82 & 62 & 58 \\
\hline
\end{tabular}

WLB: white light bronchoscopy; AFB: addition of autofluorescence bronchoscopy. LIFE-Lung system is manufactured by Xillix Technologies, Vancouver, BC, Canada; D-Lightæ system: Karl Storz Endoscopy of America, Culver City, CA, USA; Onco-LIFE $E_{\mathbb{R}}$ Novadaq Technologies, Richmond, BC, Canada

the emitted red and green autofluorescent light with two image-intensified charge-coupled device (CCD) cameras. Normal areas appear green and abnormal areas appear reddish brown, owing to reduced green autofluorescence in pre-neoplastic and neoplastic lesions.

Subsequent technological improvements made it possible to use non-image intensified CCD cameras and further development included the combination of fluorescence and reflectance imaging, in order to enhance contrast between normal and abnormal tissues. The Pinpoint system (previously Onco-LIFE ${ }_{\circledR}$; Novadaq Technologies, Richmond, BC, Canada) uses a combination of reflectance and fluorescence imaging. Blue light (395$445 \mathrm{~nm}$ ) and small amount of red light $(675-720 \mathrm{~nm})$ from a filtered mercury arc lamp is used for illumination. A red reflectance image is captured in combination with the green autofluorescence image (fig. 1) [40]. Another system utilising fluorescence and reflectance imaging is the D-Light ${ }_{\circledast}$ system (Karl Storz Endoscopy of America, Culver City, CA, USA) which consists of a RGB CCD camera and a filtered Xe lamp (380-460 nm). It combines an autofluorescence image from wavelengths $>480 \mathrm{~nm}$ with a blue reflectance image [42]. Frame averaging is used to amplify the weak autofluorescence signal.

These earlier autofluorescence systems were designed to be used with fibreoptic bronchoscopes. Autofluorescence systems
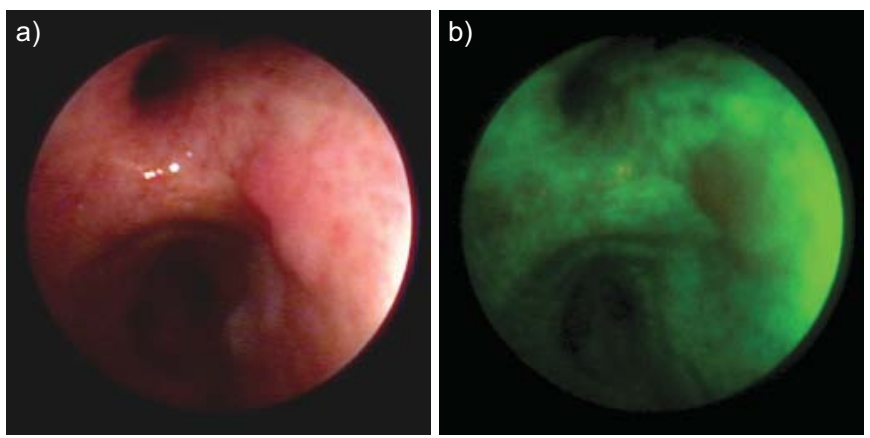

FIGURE 1. Right main bronchus carcinoma in situ under a) white light imaging and b) autofluorescence imaging with Pinpoint system (Novadaq Technologies, Mississauga, ON, Canada) that can be used with video bronchoscope systems have now been developed. The Pentax SAFE-3000 ${ }_{\circledR}$ system (Pentax Corp., Tokyo, Japan) uses a semiconductor laser diode that emits $408 \mathrm{~nm}$ wavelength light for illumination and detects autofluorescence using a single high-sensitivity colour CCD sensor in the fluorescence spectrum $(430-700 \mathrm{~nm})$. Reflected blue light is used to generate a fluorescence-reflectance image. The white light and fluorescence images can also be made displayed simultaneously (figs 2 and 3) [59]. The Olympus autofluorescence video bronchoscope (AFI-Lucera ${ }^{\circledR}$ system; Olympus Corp., Tokyo, Japan) uses blue light (395-445 nm) for illumination. An autofluorescence image (490-700 nm), as well as two reflectance images, one green $(550 \mathrm{~nm})$ and one red $(610 \mathrm{~nm})$, are captured sequentially and integrated by a video processor to produce a composite image [60].

There is a reduction in specificity associated with the increased sensitivity for detection of early lesions by autofluorescence imaging (table 1). This increase in false-positive biopsies has an impact on the cost-effectiveness of this technique. However, there are some recent data to suggest that areas with abnormal autofluorescence but benign histopathology contain increased chromosomal aberrations, and that the presence of multiple areas of abnormal autofluorescence may be an indicator of increased lung cancer risk [61, 62]. Recently, the use of a quantitative score during autofluorescence examination has been shown to improve specificity [63].

\section{Optical coherence tomography}

Optical coherence tomography (OCT) is a promising endoscopic imaging method that enables micron-scale resolution of the bronchial epithelium. It may become an imaging modality that helps address the relatively high false-positive rate of autofluorescence imaging. OCT is a noncontact method that delivers nearinfrared light to the endobronchial tissue via a small probe via a bronchoscope. It allows imaging of cellular and extracellular structures from analysis of the back-scattered light with a spatial resolution of 3-15 $\mu \mathrm{m}$ and a depth penetration of $\sim 2 \mathrm{~mm}$ to provide near-histological images in the bronchial wall [64-75]. Early studies have shown that dysplasia can be distinguished from metaplasia, hyperplasia or normal tissue and that

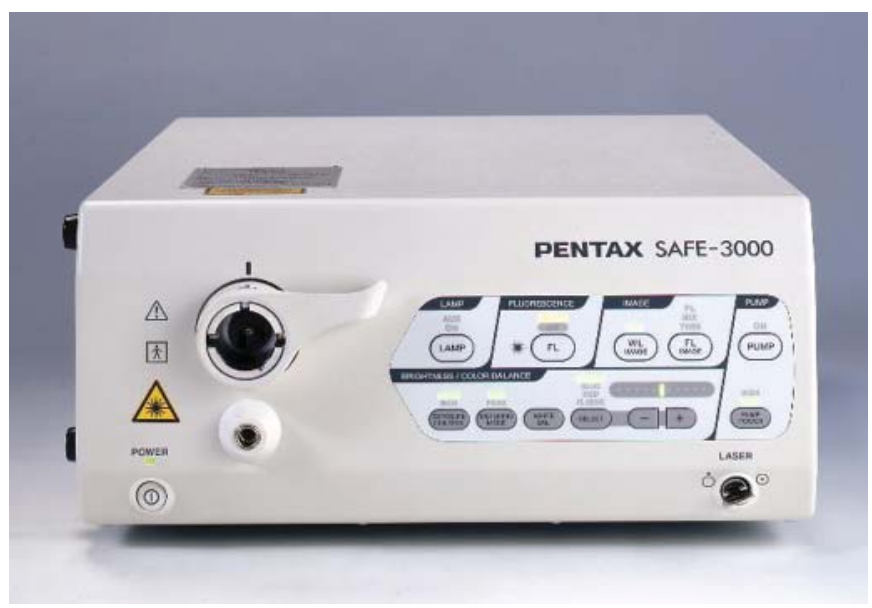

FIGURE 2. Pentax SAFE $300{ }_{\circledast}$ (Pentax Corp., Tokyo, Japan) autofluorescence bronchoscopy system. 

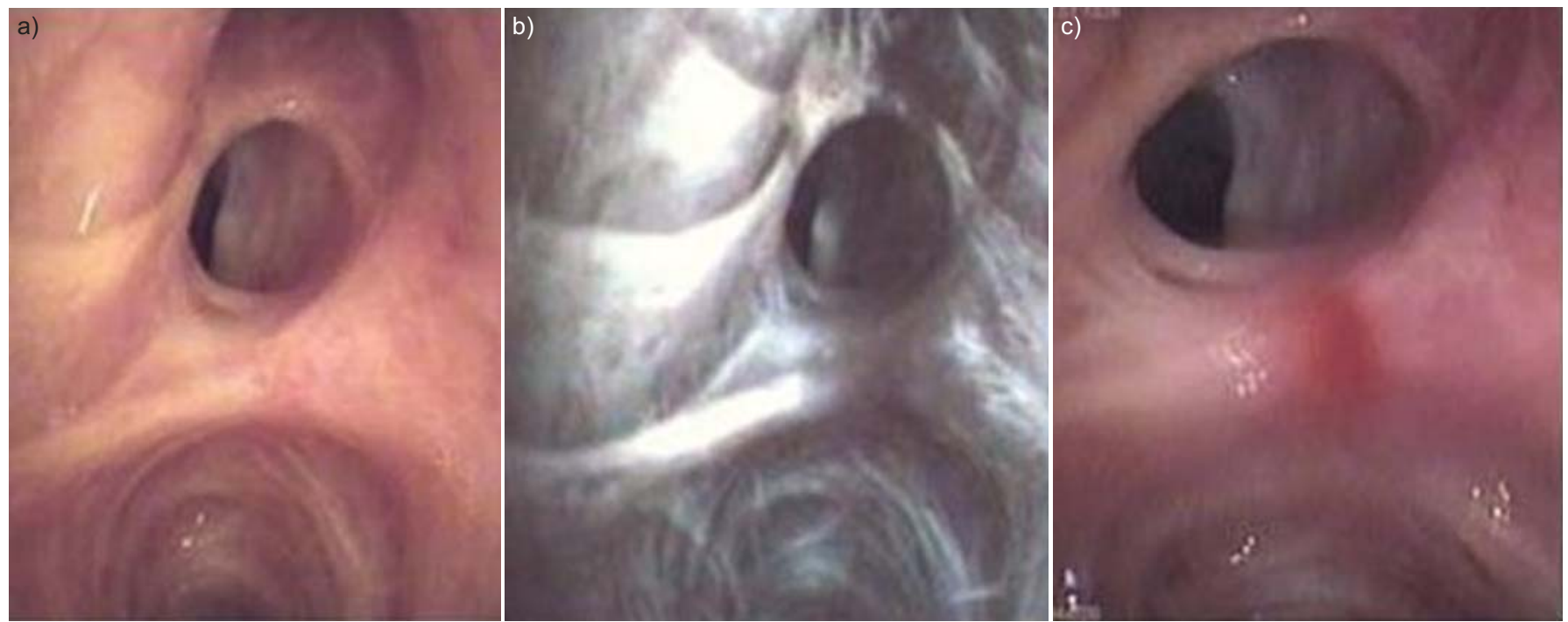

FIGURE 3. An area of carcinoma in situ at the left upper lobe carina seen using the Pentax SAFE 3000 ® system (Pentax Corp., Tokyo, Japan). a) White light imaging alone, b) autofluorescence imaging and c) dual imaging.

carcinoma in situ can be distinguished from invasive cancer [68, 69]. Severity of the histopathology grade was associated with a progressive increase in the epithelial thickness and the nuclei of the cells also became darker and less light was scattered. The basement membrane became disrupted or disappeared with invasive carcinoma (fig. 4) [69].

However, differentiation between high-grade dysplasia and carcinoma in situ could not be made with OCT. To further advance this technology, systems with higher resolution and Doppler capability that can measure both tissue microstructures in greater detail and microvascular blood flow may be useful [70]. Doppler OCT systems already exist that can detect very slow blood flow $\left(<20 \mu \mathrm{m} \cdot \mathrm{s}^{-1}\right.$ in blood vessels as small as $\sim 15 \mu \mathrm{m}$ diameter). OCT technology could prove useful for structural and functional assessment of suspicious lesions, staging (invasion of basement membrane) and feedback during endobronchial therapy $[68,70,71]$.

\section{High-magnification video bronchoscopy}

High-magnification bronchoscopy (Exera®; Olympus Optical Corp., Tokyo, Japan), combines both fibreoptic and video bronchoscope technologies to produce $100-110 \times$ better magnification of the bronchial wall compared with standard video bronchoscopes [72]. This technique enables the visualisation of microvascular networks in the bronchial mucosa. Increased vessel density in the bronchial submucosa is often present in squamous dysplasia and may play an early role in cancer pathogenesis [73]. Angiogenic squamous dysplasia is believed to be a potentially more aggressive pre-neoplastic lesion characterised by a collection of blood vessels juxtaposed to and projecting into an area of epithelial dysplasia. Increase in microvascular density can be seen under high magnification in the majority of areas of abnormal autofluorescence and enables better discrimination from mucosal inflammation [72].

\section{Narrow band imaging}

Narrow band imaging (NBI®; Olympus Optical Corp.) is a novel system that also utilises the changes seen in the microvascular network. This technique uses a narrow band filter rather than the conventional broad RGB filter used in standard video bronchoscopes. The conventional RGB filter uses 400-500 nm (blue), 500-600 nm (green) and 600-700 nm (red). NBI uses three narrow bands: $400-430 \mathrm{~nm}$ (blue; covers haemoglobin absorption at $410 \mathrm{~nm}$ ), 420-470 $\mathrm{nm}$ (blue) and 560-590 nm (green). Blue light has a short wavelength, reaches into the bronchial submucosa and is absorbed by haemoglobin. On evaluation of airway lesions that were abnormal under autofluorescence imaging, this technique provided more accurate images of microvessels compared to high-magnification video bronchoscopy using broadband RGB technology. $\mathrm{NBI}$, in comparison to standard white light video bronchoscopy, seemed to improve the detection of dysplasia/malignancy when used as an adjunct to white light in a small study [74]. Direct comparisons between narrow band imaging and autofluorescence bronchoscopy, in order to determine their relative merits, have not been conducted.

The choice of patients to investigate with these new imaging techniques, outside a research setting, remains under consideration. There is no current comprehensive lung cancer screening programme for asymptomatic smokers in Europe and North America, except in a research setting. At present, high-risk patients considered for further clinical assessment include those with sputum atypia and those with a previous, suspected or known lung cancer, particularly squamous cell carcinoma $[9,62$, 75]. The accurate prediction of those patients who are at greatest risk and those who will develop progression of pre-malignant lesions to invasive cancer will be an important clinical tool. Currently, it appears that the presence of autofluorescence abnormalities may itself be a marker of field carcinogenesis and overall lung cancer risk [20,62]. The presence of chromosomal aneusomy or a number of immunohistochemical markers in pre-invasive lesions may also be useful in prediction of lesion progression and lung cancer risk [76-80].

In summary, minimally invasive bronchoscopy-based technologies are currently available and are being further developed in 

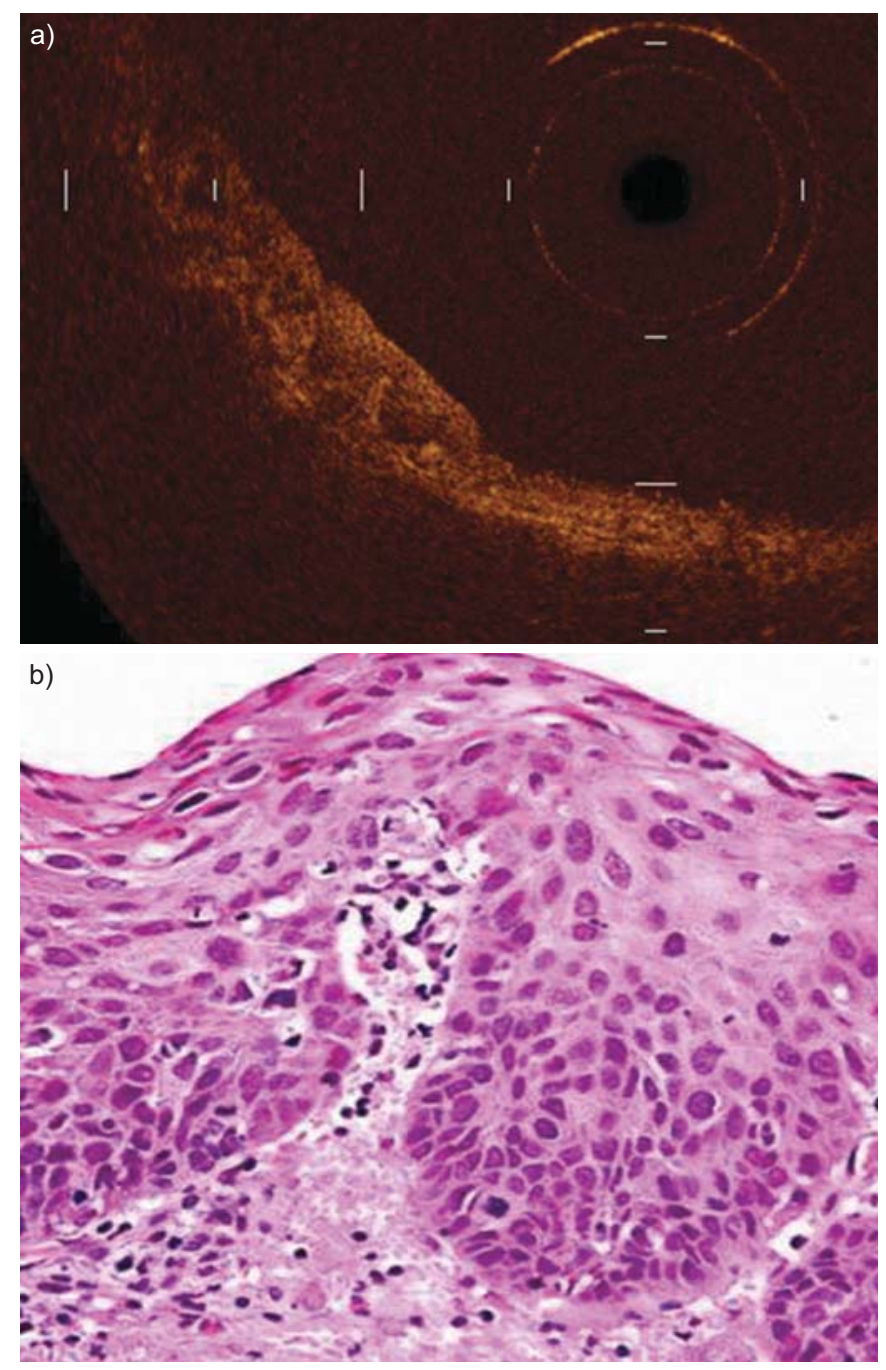

FIGURE 4. Optical coherence tomography image of a) an area of carcinoma in situ and b) corresponding haematoxylin and eosin stained histology section. Reproduced from [69] with permission from the publisher.

order to improve the accuracy for early detection of minute mucosal lesions that are clonally and potentially cancerous $[5,9$, $18,73]$. Increased interest in the study of the natural history of these lesions, for the accurate prediction of those patients at highest risk, will continue to expand our ability to comprehensively approach the dynamic processes involved in early field carcinogenesis by exploiting the potentials of various optical imaging techniques $[69,81,82]$. Together with the advancements of single-fibre endoscopy combined with more accurate fourdimensional navigation beyond the visible spectrum, and distally towards the lung parenchyma, new technologies will even expand our ability to monitor disease processes that are, as yet, still out of bronchoscopic reach [83, 84].

\section{STAGING FOR EARLY PROXIMAL LUNG CANCER PRIOR TO TREATMENT}

Lesions that have invaded into the bronchial cartilage or wall are unlikely to be curable by bronchoscopic intraluminal therapy alone [7, 11, 57]. Surgical series and clinical trials with photodynamic therapy have been helpful in identifying lesions that are amenable to curative bronchoscopic therapy $[7,8,11,85]$.
Factors predicting the response of endobronchial therapy include intraluminal tumour growth, depth of invasion and lymph node involvement. Combined imaging and diagnostic technologies should be applied in the assessment of these lesions and assist in the choice of optimal treatment. The use of autofluorescence bronchoscopy, radial transducer endobronchial ultrasound for assessing deeper tumour infiltration, highresolution thin-slice computed tomography and ${ }^{18}$ fluorodeoxyglucose (FDG) positron emission tomography (PET), in addition to clinical assessment of patients and their comorbidities, may all influence management before choosing the optimal treatment strategy [85].

\section{Bronchoscopic appearance}

For bronchoscopic therapy, bronchoscopically accessible flat superficial lesions of $\leqslant 10 \mathrm{~mm}$ diameter with clear tumour margins are potential candidates. AFB is the best imaging modality for the assessment of these features, which cannot be adequately evaluated with white light imaging alone [57, 58]. AFB has the additional benefit of detecting the potential presence of synchronous lesions, which are relatively common in subjects with centrally located squamous cell carcinoma. Up to $20 \%$ patients may have a synchronous carcinoma and up to $45 \%$ patients may have other lesions of moderate or severe dysplasia [12-15, 38, 86].

\section{Depth of invasion and lymph node assessment}

Previously, prediction of depth of invasion and lymph node involvement have depended on the bronchoscopic appearance and relatively insensitive older generation computed tomography (CT) scan machines. Endobronchial ultrasound (EBUS) can assist in the depth assessment of tumour invasion, in addition to the current sophistication of multidetector CT scans, by using a radial transducer $20 \mathrm{MHz}$ ultrasound probe inserted through the working channel of a flexible bronchoscope. This can delineate the layers of the bronchial wall apart from tumour invasion [8789]. EBUS resulted in a change in management in $36 \%$ of tumours thought to be curable by bronchoscopic therapy after white light bronchoscopy and thoracic $\mathrm{CT}$, and can be used as an adjunct to AFB in order to improve prediction of malignancy in lesions with significantly abnormal autofluorescence [90].

Thoracic CT scan can detect bronchial wall thickening, peribronchial extension and lymph node enlargement, and has been shown to alter clinical management in $22-35 \%$ of cases being considered for curative endobronchial therapy. It is also useful to exclude synchronous peripheral parenchymal cancers that may alter management [91]. The sensitivity and specificity of thoracic CT scans for the detection of lymph node metastasis is limited, at $50-70 \%$ and $66-89 \%$, respectively [92, 93]. FDG-PET scan has been shown to perform better than thoracic CT scan for the detection of lymph node metastases, with sensitivity $67-91 \%$ and specificity $82-96 \%$ [92, 93]. A recent study comparing systematic sampling with EBUStransbronchial needle aspiration (TBNA) with CT and PET scan showed that the sensitivities of CT, PET and EBUS-TBNA were 77,80 and $92 \%$, respectively; specificities were 55, 70 and $100 \%$, respectively; and diagnostic accuracies were 61, 73 and $98 \%$, respectively. The positive predictive values of CT, PET and EBUS-TBNA were 37, 47 and 100\%, respectively; negative predictive values were 88, 92 and 97\%, respectively [94]. 
Therefore, it is clear that the combined use of non- and minimally invasive imaging technologies are required to stage early proximal lung cancer adequately prior to choosing the optimal treatment strategy.

\section{TREATMENT OF EARLY PROXIMAL LUNG CANCER}

Surgery is currently still regarded as the accepted approach for the treatment of carcinoma in situ and results in 80-90\% 5-yr survival rate [6-10]. However, it remains relatively wasteful, as significant normal lung parenchyma tissue also has to be removed. To obtain a cure, up to $30 \%$ of patients with early proximal lung cancer will require bilobectomy or pneumonectomy, and the remaining $70 \%$ require lobectomy [8]. Segmentectomy has been used in small series with good 5-yr survival rates ( $>90 \%$ ) [7]. Synchronous lesions can be detected in up to $20 \%$ of patients and further metachronous lesions may develop in $14-30 \%$ of patients with central squamous cell carcinoma [4-15]. Therefore, surgery is not necessarily the only and primary choice based on considerations of significant comorbidities in this cohort of patients, owing to their smoking history, the chronic field carcinogenesis with potential developments of subsequent primaries and the necessity to conserve lung parenchyma for quality of life. Hence, there is significant interest in the use of various bronchoscopic modalities for the treatment of early central lung cancers and the reservation of surgical resection for lesions that are considered too locally advanced or those that have failed the initial bronchoscopic treatment attempt $[11,57]$.

Published comparisons of surgical resection to bronchoscopic therapy for carcinoma in situ and microinvasive squamous cell cancers do not exist and are unlikely to be performed in the near future, largely due to the infrequent occurrence of these lesions, which are often found by chance. Local bronchoscopic treatment is a straightforward and relative simple procedure, which does not hamper subsequent surgical resection in the case of treatment failure [57]. The similar outcome of early proximal lung cancers treated with bronchoscopic therapy or surgery are encouraging $[9,10,57,95,96]$.

The cost of treatment and follow-up of bronchoscopically treated small stage 1A cancers in inoperable patients was 30\% of the cost of standard surgery in matched operable patients in one published cost effectiveness analysis; obviously, surgical procedures are associated with greater morbidity [97].

\section{Bronchoscopic treatment modalities}

Treatment success with bronchoscopic techniques strongly depends on accurate staging, as has been discussed. Selected

TABLE 2 Early proximal cancer in the central airways treated with curative intent using various intraluminal bronchoscopic treatment methods

\begin{tabular}{|c|c|c|c|c|c|}
\hline Study & Technique & Stage & Size $\mathrm{cm}$ & Lesions $\mathbf{n}$ & Complete response \\
\hline Tokyo Medical University $[96,99-102]$ & PDT (HpD/Photofrin) & $\begin{array}{l}\text { Stage } 0(n=185) \\
\text { Stage } 1(n=79)\end{array}$ & $<2$ & 264 & $\begin{array}{c}84.8 \% \\
93 \% \leqslant 1 \mathrm{~cm} \\
45 \%>1 \mathrm{~cm}\end{array}$ \\
\hline SutedJA [103] & PDT (Photofrin) & $\begin{array}{c}\text { Stage } 0(n=17) \\
\text { Stage } 1 A / 1 B(n=22)\end{array}$ & NA & 39 & $\begin{array}{c}72 \% \\
\text { Stage 0 100\% } \\
\text { Stage 1A/1B 50\% }\end{array}$ \\
\hline Cortese $[104]$ & PDT (HpD) & Endobronchial & $<2$ & 23 & $\begin{array}{c}65 \% \\
88 \% \leqslant 1 \mathrm{~cm} \\
33 \%>1 \mathrm{~cm}\end{array}$ \\
\hline КАТО [105] & PDT (NPe-6) & $\begin{array}{l}\text { Stage } 0(n=23) \\
\text { Stage } 1(n=22)\end{array}$ & $<2$ & 45 & $84.6 \%$ \\
\hline UsudA [106] & PDT (NPe-6) & $\begin{array}{l}\text { Stage } 0(n=37) \\
\text { Stage } 1 A(n=1)\end{array}$ & $<2$ & 38 & $\begin{array}{l}94 \% \leqslant 1 \mathrm{~cm} \\
80 \%>1 \mathrm{~cm}\end{array}$ \\
\hline DEYGAS [107] & Cryotherapy & Stage $0 / 1 \mathrm{~A}$ & NA & 41 & $91 \%$ \\
\hline VAN BOXEM [108] & EC & $\begin{array}{c}\text { Stage } 0(n=2) \\
\text { Stage } 1 A(n=13)\end{array}$ & $\leqslant 1$ & 15 & $80 \%$ \\
\hline Vonk NoORdegraAF [109] & EC/PDT/YAG laser & Stage $1 \mathrm{~A}$ & $\leqslant 1$ & $\begin{array}{c}32 \\
26 \text { (EC) } \\
5 \text { (PDT) } \\
1 \text { (YAG) }\end{array}$ & $97 \%$ \\
\hline Pérol [110] & HDR brachytherapy & Endobronchial & $\leqslant 1$ & 21 & $75 \%$ \\
\hline MARSIGLIA [111] & HDR brachytherapy & Endobronchial & NA & 34 & $85 \%$ \\
\hline Cavaliere [112] & Nd:YAG laser & Stage 0 & NA & 38 & $63 \%$ \\
\hline
\end{tabular}

PDT: photodynamic therapy; HpD: haematoporphyrin derivative; NPe-6: N-aspartyl chlorin e6; EC: electrocautery; YAG: yttrium-aluminium-garnet; HDR: high dose rate; NA: information not available. Photofrin is manufacturered by Axcan Pharma, Mont-Saint-Hilaire, QC, Canada. 
lesions should be limited to mostly flat-type squamous cell carcinoma in situ and microinvasive cancer of $<1 \mathrm{~cm}$ with clearly visible distal tumour margins under AFB examination, while tumour invasion can be accurately excluded by EBUS. It is also obvious that lesions with nodal involvement cannot be regarded as early stage proximal lung cancer.

In the field of interventional pulmonology, many bronchoscopic therapeutic alternatives are currently applicable using various fibres and applicators through the working channel of the flexible bronchoscope. Consensus guidelines exist and have been previously published, and will therefore not be further described in detail $[9,22,98]$. Treatment techniques include: photodynamic therapy (PDT) using photosensitisers in combination with laser excitation; thermal coagulation using electrocautery, argon plasma coagulation or Nd:YAG (neodymium-doped yttriumaluminium-garnet) laser; and cryotherapy using repetitive freezing and slow thawing and intraluminal irradiation or brachytherapy (mostly high dose rate). In general, the cure rate after these bronchoscopic techniques is in the range of $43-97 \%$ (table 2). A significant number of lesions may recur after treatment or require a second treatment to obtain cure $[19,86$, 104]. However, failures are usually due to more extensive disease than seen on the original assessment [86, 108]. Many of the published series with these techniques include larger stage 1A tumours rather than limiting treatment to carcinoma in situ or microinvasive disease. In addition, many were performed without the assistance of more recent technologies, such as EBUS, AFB and PET imaging to assess lesion suitability. The success is clearly dependent on the stringent application of selection criteria for appropriate lesions, with a better response seen to correspond with lesions of smaller size (table 2) [113]. Less airway scarring and stenosis has been seen with electrocautery compared with PDT or YAG laser therapy [95]. These alternative bronchoscopic treatments emerged from the extensive experience of immediate palliative tumour debulking in dealing with imminent suffocation and larger airway obstruction. Their established role in lung cancer care have provided us with safe, quick and effective treatment alternatives for early proximal lung cancers that are intraluminally located [57, 98].

Previous reports have dealt with relatively small numbers of patients treated bronchoscopically as the majority of early proximal lung cancers are accidental findings. These lesions are often diagnosed during the clinical surveillance of highrisk individuals with various smoking-related (co)morbidities and in those after curative treatment of previous aerodigestive cancer [9]. This in itself is a valid argument for careful assessment of alternative treatment options prior to the consideration of surgical resection as the primary therapeutic choice. Bronchoscopic strategies are clearly less morbid and less toxic even if compared with radiotherapy [114]. For selected early central lung cancers, simple techniques such as electrocautery, argon plasma coagulation and cryotherapy can be conducted safely and quickly under local anaesthesia in the outpatient setting and provide superior cost-effectiveness [97].

\section{REFERENCES}

1 Jemal A, Siegel R, Ward E, et al. Cancer statistics 2006. CA Cancer J Clin 2006; 56: 106-130.
2 Woodward RM, Martin ML, Cronin KA, Cutler DM. The value of medical interventions for lung cancer in the elderly. Results from SEER-CMHSF. Cancer 2007; 110: 2511-2518.

3 Janssen-Heijnen ML, Coeburgh JW. Trends in incidence and prognosis of the histological subtypes of lung cancer in North America, Australia, New Zealand and Europe. Lung Cancer 2001; 31: 123-137.

4 Sato M, Saito Y, Endo C, et al. The natural history of radiographically occult bronchogenic squamous cell carcinoma: a retrospective study of overdiagnosis bias. Chest 2004; 126: 108-113.

5 Breuer RH, Pasic A, Smit EF, et al. The natural course of preneoplastic lesions in bronchial epithelium. Clin Cancer Res 2005; 11: 537-543.

6 Cortese D, Pairolero P, Bergstralh E, et al. Roentgenographically occult lung cancer. A ten-year experience. J Thorac Cardiovasc Surg 1983; 86: 373-380.

7 Fujimura S, Sagawa M, Saito Y, et al. A therapeutic approach to roentgenographically occult squamous cell carcinoma of the lung. Cancer 2000; 89: Suppl. 11, 2445-2448.

8 Nakamura H, Kawasaki N, Hagiwara M, et al. Early hilar lung cancer - risk for multiple lung cancers and clinical outcome. Lung Cancer 2001; 33: 51-57.

9 Kennedy TC, McWilliams A, Edell E, et al. American College of Chest Physicians. Bronchial intraepithelial neoplasia/early central airways lung cancer: ACCP evidence-based clinical practice guidelines (2nd edition). Chest 2007; 132: Suppl. 3, 221S-233S.

10 Woolner L, Fontana R, Cortese D, et al. Roentgenographically occult lung cancer; pathologic findings and frequency of multicentricity during a 10-year period. Mayo Clin Proc 1984; 59: 453-466.

11 Vonk-Noordegraaf A, Postmus P, Sutedja T. Bronchoscopic treatment of patients with intraluminal microinvasive radiographically occult lung cancer not eligible for surgical resection: a follow-up study. Lung Cancer 2003; 39: 49-53.

12 Lam S, MacAulay C, Hung J, LeRiche J, Profio A, Palcic B. Detection of dysplasia and carcinoma in situ with a lung imaging fluorescence endoscope device. I Thorac Cardiovasc Surg 1993; 105: 1035-1040.

13 Pierard P, Vermylen P, Bosschaerts T, et al. Synchronous roentgenographically occult lung carcinoma in patients with resectable primary lung cancer. Chest 2000; 117: 779-785.

14 Pierard P, Faber J, Hutsebaut J, et al. Synchronous lesions detected by autofluorescence bronchoscopy in patients with high-grade preinvasive lesions and occult invasive squamous cell carcinoma of the proximal airways. Lung Cancer 2004; 46: 341-347.

15 van Rens M, Schramel F, Elbers J, Lammers J. The clinical value of lung imaging fluorescence endoscopy for detecting synchronous lung cancer. Lung Cancer 2001; 32: 13-18.

16 Venmans B, van Boxem T, Smit E, Postmus P, Sutedja T. Outcome of bronchial carcinoma in situ. Chest 2000; 117: 1572-1576.

17 Deygas N, Froudarakis M, Ozenne G, Vergnon JM. Cryotherapy in early superficial bronchogenic carcinoma. Chest 2001; 120: 26-31. 
18 Bota S, Auliac J, Paris C, et al. Follow-up of bronchial precancerous lesions and carcinoma in situ using fluorescence endoscopy. Am J Respir Crit Care Med 2001; 164: 1688-1693.

19 Moro-Sibilot D, Fievet F, Jeanmart M, et al. Clinical prognostic indicators of high-grade pre-invasive bronchial lesions. Eur Respir J 2004; 24: 24-29.

20 George P, Banerjee A, Read C, et al. Surveillance for the detection of early lung cancer in patients with bronchial dysplasia. Thorax 2007; 62: 43-50.

21 Terzi A, Pelosi G, Falezza G, Lonardoni A, Pasini F, Calabrò F. Early hilar lung cancer - clinical aspects and long term survival. Identification of a subgroup of stage IA patients with more favorable prognosis. Lung Cancer 2000; 27: 119-124.

22 Bolliger CT, Sutedja TG, Strausz J, Freitag L. Therapeutic bronchoscopy with immediate effect: laser, electrocautery, argon plasma coagulation and stents. Eur Respir J 2006; 27: 1258-1271.

23 Motherby H, Nicklaus S, Berg A, et al. Semiautomated monolayer preparation of bronchial secretions using AutoCyte PREP. Acta Cytol 1999; 43: 47-57.

24 Agusti C, Xaubet A, Monton C, et al. Induced sputum in the diagnosis of peripheral lung cancer not visible endoscopically. Respir Med 2001; 95: 822-828.

25 Choi YD, Han CW, Kim JH, et al. Effectiveness of sputum cytology using ThinPrep method for evaluation of lung cancer. Diagn Cytopathol 2008; 36: 167-171.

26 Holiday DB, McLarty JW, Farley ML, et al. Sputum cytology within and across laboratories. A reliability study. Acta Cytol 1995; 39: 195-206.

27 Byers T, Wolf HJ, Franklin WA, et al. Sputum cytologic atypia predicts incident lung cancer: defining latency and histologic specificity. Cancer Epidemiol Biomarkers Prev 2008; 17: 158-162.

28 van Oppen Toth, Meisels A, St-Pierre S. Malignancy associated changes in sputum: a correlated study of 315 patients. Acta Cytol 1975; 19: 573-576.

29 MacAulay C, Lam S, Payne P, LeRiche J, Palcic B. Malignancy associated changes in bronchial epithelial cells in biopsies. Anal Quant Cytol Histol 1995; 17: 55-61.

30 Ikeda N, MacAulay C, Lam S, et al. Malignancy associated changes in bronchial epithelial cells and clinical application as a biomarker. Lung Cancer 1998; 19: 161-166.

31 Palcic B, Garner DM, Beveridge J, et al. Increase of sensitivity of sputum cytology using high-resolution image cytometry: field study results. Cytometry 2002; 50: 168-176.

32 Xing S, Khanavkar B, Nakhosteen JA, et al. Predictive value of image cytometry for diagnosis of lung cancer in heavy smokers. Eur Respir J 2005; 25: 956-963.

33 Kemp RA, Reinders DM, Turic B. Detection of lung cancer by automated sputum cytometry. J Thorac Oncol 2007; 2: 993-1000.

34 Marek W, Richartz G, Philippou S, Marek L, KotschyLang N. Sputum screening for lung cancer in radon exposed uranium miners: a comparison of semi-automated sputum cytometry and conventional cytology. J Physiol Pharmacol 2007; 58: Suppl. 5, 349-361.
35 Chhajed PN, Shibuya K, Hoshino H, et al. A comparison of video and autofluorescence bronchoscopy in patients at high risk of lung cancer. Eur Respir J 2005; 25: 951-955.

36 Shibuya K, Hoshino H, Chiyo M, et al. Subepithelial vascular patterns in bronchial dysplasias using a high magnification bronchovideoscope. Thorax 2002; 57: 902-907.

37 Wagnieres G, McWilliams A, Lam S. Lung cancer imaging with fluorescence endoscopy. In: Mycek M, Pogue B, eds. Handbook of Biomedical Fluorescence. New York, Marcel Dekker, 2003; pp. 361-396.

38 Lam S, Kennedy $\mathrm{T}$, Unger M, et al. Localization of bronchial intraepithelial neoplastic lesions by fluorescence bronchoscopy. Chest 1998; 113: 696-702.

39 Ernst A, Simoff MJ, Mathur PN, Yung RC, Beamis Jr JF. D-light autofluorescence in the detection of premalignant airway changes: a multicenter trial. J Bronchol 2005; 12: 133-138.

40 Edell E, Lam S, Pass H, et al. Detection and localization of intraepithelial neoplasia and invasive carcinoma using fluorescence-reflectance bronchoscopy: an international, multicenter clinical trial. J Thorac Oncol 2009; 4: 49-54.

41 Hirsch FR, Prindiville SA, Miller YE, et al. Fluorescence versus white-light bronchoscopy for detection of preneoplastic lesions: a randomized study. J Natl Cancer Inst 2001; 93: 1385-1391.

42 Häussinger K, Becker H, Stanzel F, et al. Autofluorescence bronchoscopy with white light bronchoscopy compared with white light bronchoscopy alone for the detection of precancerous lesions: a European randomized controlled multicentre trial. Thorax 2005; 60: 496-503.

43 Hung J, Lam S, leRiche J, Palcic B. Autofluorescence of normal and malignant bronchial tissue. Laser Surg Med 1991; 11: 99-105.

$44 \mathrm{Qu} \mathrm{J}$, MacAulay C, Lam S, Palcic B. Laser-induced fluorescence spectroscopy at endoscopy: tissue optics, monte carlo modeling, and in vivo measurements. Opt Eng 1995; 34: 3334-3343.

45 Qu J, MacAulay C, Lam S, Palcic B. Optical properties of normal and carcinoma bronchial tissue. Appl Optics 1994; 33: 7397-7405.

46 Lam S, MacAulay C, Leriche J, Ikeda N, Palcic B. Early localization of bronchogenic carcinoma. Diagn Ther Endosc 1994; 1: 75-78.

47 Lam S, MacAulay C, Leriche J, Palcic B. Detection and localization of early lung cancer by fluorescence bronchoscopy. Cancer 2000; 89: Suppl. 11, 2468-2473.

48 Venmans BJW, van Boxem AJM, Smit EF, et al. Early detection of preinvasive lesions in high-risk patients. A comparison of conventional flexible and fluorescence bronchoscopy. J Bronchology 1998; 5: 280-283.

49 Vermylen P, Pierard P, Roufosse C, et al. Detection of bronchial preneoplastic lesions and early lung cancer with fluorescence bronchoscopy: a study about its ambulatory feasibility under local anesthesis. Lung Cancer 1999; 25: 161-168.

50 Horvath T, Horvathova M, Salajka F, et al. Detection of bronchial neoplasia in uranium miners by autofluorescence bronchoscopy. Diagn Ther Endosc 1999; 5: 91-98.

51 Kusunoki Y, Imamura F, Uda H, Mano M, Horai T. Early detection of lung cancer with laser-induced fluorescence 
endoscopy and spectrofluorometry. Chest 2000; 118: 1776-1782.

52 Shibuya $\mathrm{K}$, Fujisawa $\mathrm{T}$, Hoshino $\mathrm{H}$, et al. Fluorescence bronchoscopy in the detection of preinvasive bronchial lesions in patients with sputum cytology suspicious or positive for malignancy. Lung Cancer 2001; 32: 19-25.

53 Sato M, Sakurada A, Sagawa M, et al. Diagnostic results before and after introduction of autofluorescence bronchoscopy in patients suspected of having lung cancer detected by sputum cytology in lung cancer mass screening. Lung Cancer 2001; 32: 247-253.

54 Goujon D, Zellweger M, Radu A, et al. In vivo autofluorescence imaging of early cancers in the human tracheobronchial tree with a spectrally optimized system. Biomed Opt Journal 2003; 8: 17-25.

55 Fielding D. Practical issues in autofluorescence bronchoscopy with Storz D Light bronchoscope. Photodiagn Photodynam Ther 2004; 1: 247-251.

56 Kennedy TC, Franklin WA, Prindiville SA, et al. High prevalence of occult endobronchial malignancy in high risk patients with moderate sputum atypia. Lung Cancer 2005; 49: 187-191.

57 Sutedja TG, Codrington H, Risse EK, et al. Autofluorescence bronchoscopy improves staging of radiographically occult lung cancer and has an impact on therapeutic strategy. Chest 2001; 120: 1327-1332.

58 Ikeda N, Hiyoshi T, Kakihana M, et al. Histopathological evaluation of fluorescence bronchoscopy using resected lungs in cases of lung cancer. Lung Cancer 2003; 41: 303-309.

59 Ikeda N, Honda H, Hayashi A, et al. Early detection of bronchial lesions using newly developed videoendoscopybased autofluorescence bronchoscopy. Lung Cancer 2006; 52: 21-27.

60 Chiyo M, Shibuya K, Hoshino H, et al. Effective detection of bronchial preinvasive lesions by a new autofluorescence imaging bronchovideoscope system. Lung Cancer 2005; 48: 307-313.

61 Helfritzsch H, Junker K, Bartel M, Scheele J. Differentiation of positive autofluorescence bronchoscopy findings by comparative genomic hybridization. Oncol Rep 2002; 9: 697-701.

62 Pasic A, Vonk-Noordegraaf A, Risse EK, Postmus PE, Sutedja TG. Multiple suspicious lesions detected by autofluorescence bronchoscopy predict malignant development in the bronchial mucosa in high risk patients. Lung Cancer 2003; 41: 295-301.

63 Lee P, McWilliams A, Lam S, Sutedja T. Quantitative image analysis for intra-epithelial neoplasia. J Thorac Oncol 2007; 2: Suppl. 4, S812.

64 Huang D, Swanson EA, Lin CP, Schuman JS, et al. Optical coherence tomography. Science 1991; 254: 1178-1181.

65 Fujimoto JG, Brezinski ME, Tearney GJ, et al. Biomedical imaging and optical biopsy using optical coherence tomography. Nat Med 1995; 1: 970-972.

66 Tearney GJ, Brezinski ME, Bouma BE, et al. In vivo endoscopic optical biopsy with optical coherence tomography. Science 1997; 276: 2037-2039.

67 Tsuboi M, Hayashi A, Ikeda N, et al. Optical coherence tomography in the diagnosis of bronchial lesions. Lung Cancer 2005; 49: 387-394.
68 Whiteman SC, Yang Y, van Pittius DG, Stephens M, Parmer J, Spiteri MA. Optical coherence tomography: real-time imaging of bronchial airways microstructure and detection of inflammatory/neoplastic morphological changes. Clin Cancer Res 2006; 12: 813-818.

69 Lam S, Standish B, Baldwin C, et al. In-vivo optical coherence tomography imaging of pre-invasive bronchial lesions. Clin Cancer Res 2008; 14: 2006-2011.

70 Yang VX, Vitkin IA. Principles of Doppler optical coherence tomography. In: Regar E, van Leeuwen T, Serruys P. Handbook of Optical Coherence Tomography in Cardiology. Oxford, Taylor and Francis Medical, 2006; pp. 305-318.

71 Li H, Standish BA, Mariampillai A, et al. Feasibility of interstitial Doppler optical coherence tomography for in vivo detection of microvascular changes during photodynamic therapy. Lasers Surg Med 2006; 38: 754-761.

72 Shibuya K, Hoshino H, Chiyo M, et al. High magnification bronchovideoscopy combined with narrow band imaging could detect capillary loos of angiogenic squamous dysplasia in heavy smokers at high risk for lung cancer. Thorax 2003; 58: 989-995.

73 Keith R, Miller Y, Gemmill R, et al. Angiogenic squamous dysplasia in bronchi of individuals at high risk for lung cancer. Clinic Cancer Res 2000; 6: 1616-1625.

74 Vincent B, Fraig M, Silvestri G. A pilot study of narrowband imaging compared to white light bronchoscopy for evaluaton of normal airways and premalignant and malignant airways disease. Chest 2007; 131: 1794-1799.

75 Moro-Sibilot D, Jeanmart M, Lantuejoul S, et al. Cigarette smoking, preinvasive bronchial lesions, and autofluorescence bronchoscopy. Chest 2002; 122: 1902-1908.

76 Jonsson S, Varella-Garcia M, Miller YE, et al. Chromosomal aneusomy in bronchial high-grade lesions is associated with invasive lung cancer. Am J Respir Crit Care Med 2008; 177: 342-347.

77 Jeanmart M, Lantuejoul S, Fievet F, et al. Value of immunohistochemical markers in preinvasive bronchial lesions in risk assessment of lung cancer. Clin Cancer Res 2003; 9: 2195-2203.

78 Breuer R, Snijders P, Sutedja T, et al. Suprabasal p53 immunostaining in premalignant endobronchial lesions in combination with histology is associated with bronchial cancer. Lung Cancer 2003; 40: 165-172.

79 Miyazu Y, Miyazawa T, Hiyama K, et al. Telomerase expression in noncancerous bronchial epithelia is a possible marker of early development of lung cancer. Cancer Res 2005; 65: 9623-9627.

80 Hoshino H, Shibuya K, Chiyo M, et al. Biological features of bronchial squamous dysplasia followed up by autofluorescence bronchoscopy. Lung Cancer 2004; 46: 187-196.

81 Thiberville L, Moreno-Swirc S, Vercauteren T, Peltier E, Cavé C, Bourg Heckly G. In vivo imaging of the bronchial wall microstructure using fibered confocal fluorescence microscopy. Am J Respir Crit Care Med 2007; 175: 22-31.

82 Huang Z, McWilliams A, Lui H, McLean DI, Lam S, Zeng H. Near-infrared Raman spectroscopy for optical diagnosis of lung cancer. Int J Cancer 2003; 107: 1047-1052.

83 Seibel EJ, Smithwick QY. Unique features of optical scanning, single fiber endoscopy. Lasers Surg Med 2002; 30: $177-183$. 
84 Anantham D, Feller-Kopman D, Shanmugham LN, et al. Electromagnetic navigation bronchoscopy-guided fiducial placement for robotic stereotactic radiosurgery of lung tumors: a feasibility study. Chest 2007; 132: 930-935.

85 Konaka C, Hirano T, Kato $\mathrm{H}$, et al. Comparison of endoscopic features of early-stage squamous cell lung cancer and histological findings. Br J Cancer 1999; 80: 1435-1439.

86 Furukawa K, Kato H, Konaka C, Okunaka T, Usuda J, Ebihara Y. Locally recurrent central-type early stage lung cancer $<1.0 \mathrm{~cm}$ in diameter after complete remission by photodynamic therapy. Chest 2005; 128: 3269-3275.

87 Kurimoto N, Murayama M, Yoshioka S, Nishisaka T, Inai K, Dohi K. Assessment of usefulness of endobronchial ultrasonography in determination of depth of tracheobronchial tumor invasion. Chest 1999; 115: 1500-1506.

88 Miyazu Y, Miyazawa T, Kurimoto N, Iwamoto Y, Kanoh K, Kohno N. Endobronchial ultrasonography in the assessment of centrally located early-stage lung cancer before photodynamic therapy. Am J Respir Crit Care Med 2002; 165: 832-837.

89 Takahashi H, Sagawa M, Sato M, et al. A prospective evaluation of transbronchial ultrasonography for assessment of depth of invasion in early bronchogenic squamous cell carcinoma. Lung Cancer 2003; 42: 42-49.

90 Herth F, Becker H, LoCicero J, Ernst A. Endobronchial ultrasound improves classification of suspicious lesions detected by autofluorescence bronchoscopy. J Bronchol 2003; 10: 249-252.

91 Pasic A, Brokx HA, Comans EF, et al. Detection and staging of preinvasive lesions and occult lung cancer in the central airways with ${ }^{18} \mathrm{~F}$-fluorodeoxyglucose positron emission tomography: a pilot study. Clin Cancer Res 2005; 11: 6186-6189.

92 Gould M, Kuschner W, Rydzak C, et al. Test performance of positron emission tomography and computed tomography for mediastinal staging in patients with nonsmall-cell lung cancer: a meta-analysis. Ann Intern Med 2003; 139: 879-992.

93 Toloza E, Harpole L, McCrory DC. Noninvasive staging of non-small cell lung cancer: a review of the current evidence. Chest 2003; 123: Suppl. 1, 137S-146S.

94 Yasufuku K, Nakajima T, Motoori K, et al. Comparison of endobronchial ultrasound, positron emission tomography, and CT for lymph node staging of lung cancer. Chest 2006; 130: 710-718.

95 van Boxem A, Westerga J, Venmans B, Postmus P, Sutedja G. Photodynamic therapy, Nd-YAG laser and electrocautery for treating early-stage intraluminal cancer: which to choose? Lung Cancer 2001; 31: 31-36.

96 Furuse K, Fukuoka M, Kato H, et al. A prospective phaseII study on photodynamic therapy for centrally located early-stage lung cancer. J Clin Oncol 1993; 11: 1852-1857.

97 Pasic A, Brokx HA, Vonk Noordegraaf A, Paul RM, Postmus PE, Sutedja TG. Cost-effectiveness of early intervention: comparison between intraluminal bronchoscopic treatment and surgical resection for T1N0 lung cancer patients. Respiration 2004; 71: 391-396.

98 Bolliger CT, Mathur PN, Beamis JF, et al. ERS/ATS statement on interventional pulmonology. European
Respiratory Society/American Thoracic Society. Eur Respir J 2002; 19: 356-373.

99 Hayata Y, Kato H, Konaka C, Ono J, Takizawa N. Hematoporphyrin derivative and laser photoradiation in the treatment of lung cancer. Chest 1982; 81: 269-277.

100 Kato H. Photodynamic therapy for lung cancer - a review of 19 years' experience. J Photochem Photobiol B 1998; 42: 96-99.

101 Kato H, Harada M, Usuda J, Tsuchida T, Okunaka T. Photodynamic therapy (PDT) of lung cancer: experience of the Tokyo Medical University. Photodiagn Photodynam Ther B 2004; 1: 49-55.

102 Usuda J, Kato H, Okunaka T, et al. Photodynamic therapy using Laserphyrin for centrally located early stage lung cancer. J Clin Oncol 2006; 24: Suppl. 18S, 7229.

103 Sutedja T, Lam S, LeRiche J, Postmus P. Response and pattern of failure after photodynamic therapy for intraluminal stage 1 lung cancer. J Bronchol 1994; 1: 295-298.

104 Cortese D, Edell E, Kinsey J. Photodynamic therapy for early stage squamous cell carcinoma of the lung. Mayo Clin Proc 1997; 72: 595-602.

105 Kato H, Furukawa K, Sato M, et al. Phase II clinical study of photodynamic therapy using mono-L-aspartyl chlorin e6 and diode laser for early superficial squamous cell carcinoma of the lung. Lung Cancer 2003; 42: 103-111.

106 Usuda J, Tsutsui $\mathrm{H}$, Honda $\mathrm{H}$, et al. Photodynamic therapy for lung cancers based on novel photodynamic diagnosis using talaporfin sodium (NPe6) and autofluorescence bronchoscopy. Lung Cancer 2007; 58: 317-323.

107 Deygas N, Froudarakis M, Ozenne G, Vergnon JM. Cryotherapy in early superficial bronchogenic carcinoma. Chest 2001; 120: 26-31.

108 Van Boxem T, Venmans B, Schramel F, et al. Radiographically occult lung cancer treated with fiberoptic bronchoscopic electrocautery: a pilot study of a simple and inexpensive technique. Eur Respir J 1998; 11: 169-172.

109 Vonk Noordegraaf A, Postmus PE, Sutedja TG. Bronchoscopic treatment of patients with intraluminal microinvasive radiographically occult lung cancer not eligible for surgical resection: a follow-up study. Lung Cancer 2003; 39: 49-53.

110 Pérol M, Caliandro R, Pommier P, et al. Curative irradiation of limited endobronchial carcinomas with high dose brachytherapy: results of a pilot study. Chest 1997; 111: 1417-1423.

111 Marsiglia H, Baldeyrou P, Lartigau E, et al. High-doserate brachytherapy as sole modality for early-stage endobronchial carcinoma. Int J Radiation Oncol Biol Phys 2000; 47: 665-672.

112 Cavaliere S, Foccoli P, Toninelli C. Curative bronchoscopic laser therapy for surgically resectable tracheobronchial tumors. J Bronchol 2002; 9: 90-95.

113 Sutedja G, van Boxem AJ, Postmus PE. The curative potential of intraluminal bronchoscopic treatment for early-stage non-small-cell lung cancer. Clin Lung Cancer 2001; 2: 264-270.

114 Timmerman R, McGarry R, Yiannoutsos C, et al. Excessive toxicity when treating central tumors in a phase II study of stereotactic body radiation therapy for medically inoperable early-stage lung cancer. J Clin Oncol 2006; 24: 4833-4839. 